\title{
EDEMA-REDUCING ACTIVITY OF SARGASSUM CRASSIFOLIUM B-GLUCAN (LAMINARAN) ON EDEMA-INDUCED RATTUS NORVEGICUS
}

\author{
ANIES CHAMIDAH*, ASEP A PRIHANTO, HARDOKO HARDOKO \\ Department of Fishery Product Technology, Faculty of Fisheries and Marine Science, Brawijaya University, Indonesia. \\ Email: achamidah@yahoo.co.id
}

Received: 17 March 2017, Revised and Accepted: 17 April 2017

\section{ABSTRACT}

Objectives: The aim of this study is to investigate anti-inflammatory activity of $\beta$-glucan (laminaran) of brown algae, Sargassum crassifolium which was extracted by using two different methods, $\beta$-glucan laminaran acid extract (LAE) and laminaran modified extract (LME).

Methods: $\beta$-glucan (laminaran) of brown algae, S. crassifolium have been extracted using two different methods, namely, $\beta$-glucan LAE and LME. The edema reducing activity of the extracts was investigated with carrageenan-induced leg edema male of Rattus norvegicus as a model.

Results: The swelling of edema was strongly inhibited by the treatment of LME with a percentage of $81.62 \%$ after $3^{\text {rd }}$ hr. It also found that the size of edema were inhibited by all treatments with the value ranging from $25.49 \%$ to $81.68 \%$. Smallest edema size was found on LME treatment, with a size of $0.68 \pm 0.09 \mathrm{~mm}$ where the control was about $0.92 \mathrm{~mm}$. Furthermore, all $\beta$-glucan-treated mice showed lower edema size compared to control.

Conclusion: It was obvious that all type of laminaran had anti-inflammatory activity. LME is the best method for production of $\beta$-glucan (laminaran) with high anti-inflammatory activity. Hence, in this study, we reported a new anti-inflammatory agent derived from S. crassifolium.

Keywords: $\beta$-glucan (laminaran), Edema, Sargassum crassifolium, Carrageenan, Edema.

(C) 2017 The Authors. Published by Innovare Academic Sciences Pvt Ltd. This is an open access article under the CC BY license (http://creativecommons. org/licenses/by/4. 0/) DOI: http://dx.doi.org/10.22159/ajpcr.2017.v10i7.18523

\section{INTRODUCTION}

Exploration of marine natural resources have been attracting scientist attention. Many resources, such algae, microorganism, wait to be explored [1,2]. One of the potential algae is brown algae, Sargassum sp. Sargassum grouped in order of Fucales. Many species are distributed over tropical regions, including Indonesia. This algae is a source of $\beta$-glucan (laminaran), linear polysaccharide composed of $\beta$ - $(1,3)$-linked glucose in its main chain, with $\beta$ - $(1,6)$-linked -chain branch differed depending on the variant of the isolated species, as well as the predicted environmental factors directly affect the biological properties [3,4]. By far, exploration of brown algae Sargassum sp. for its uses as anti-inflammatory, anti-infective, antimicrobial, anticholesterol, antioxidant, antitumor, and antiaging agents has attract many marine biologist as well as marine biotechnologist $[5,6]$.

Inflammation is a local response of living mammals' injured tissue. It is a defense reaction of the body to eliminate or limit the spread of harmful agents [7]. Complex occurrences and mediators involved in the inflammatory reaction could cause or worsen [8] the condition. There are various components to inflammatory reactions contributing to the symptoms associated with tissue injury. Edema, leukocyte infiltration, and granuloma formations are components representing inflammatory condition [9].

In this study, we investigate the potency of $\beta$-glucan (laminaran) derived from brown algae, Sargassum crassifolium for anti-inflamatory agent through edema reducing activity.

\section{METHODS}

Materials and equipment

Materials used in this study were S. crassifolium. They harvested from Talango Island, Madura, Indonesia. All chemicals agents such $\lambda$ carrageenan, phenyl butazone (Sigma Aldrich, USA), and ethylphenyl propiolate (EPP) (Fluka, Japan) including other materials such as rivanol and alcohol $70 \%$ are analytical grades.

\section{Preparation of $\beta$-glukan (laminaran) extract}

The brown alga, $S$. crassifolium, was sun dried. The samples chopped into pieces and then filtered to obtain powder. Algae was extracted using Yvin et al. and Mohan et al. $[10,11]$ method with modification. Using two different extraction tools, the hot plate magnetic stirrer (HPMS) and ultra-sonication. $\beta$-glucan (laminaran) generated from HPMS with sulfuric acid as a solution called laminaran acid extract (LAE). For the result of the ultrasonic method with distilled water as solution, the extract called laminaran modified extract (LME).

\section{Test animal}

40 male rat (20 for paw edema and 20 Wistar rats for ear edema experiments) with the weight of $180-200 \mathrm{~g}$ used as test animals. Each of them placed in individual cages. The wistar rat kept under standard environmental conditions and had free access to diet and water (ad libitum). All of these animals acclimatized for a week before testing period. All experimental procedures conducted by following the guidelines of Brawijaya University Animal Ethics Committee.

Anti-inflammatory activity test with carrageenan hind paw edema 20 rat divided into 4 groups, each of 5 wistar rat, treated with the administered extracts a similar concentration of $375 \mathrm{mg} / \mathrm{sample}$, while a controlwasleftwithouttreatment.Edemawasinducedby $100 \mathrm{uLsubplantar}$ injection containing $1 \%$ solution of carrageenan suspended in fresh $0.9 \%$ $\mathrm{NaCl}$ solution. The solution injected into the subplantar tissue of the right rear leg of Wistar rat. Linear foot circumference measured at intervals of 1,3 , and $5 \mathrm{hrs}$. Anti-inflammatory activity measured as the percentage reduction of edema relative to controls after topical medications [12].

\section{Mouse ear swelling assays (MESA) with EPP}

The ear swelling test conducted using a method modified from Frenkel [13], in which the ears of wistar rat subcutaneously injected 
with EPP for hypersensitivity test Nualkaew et al. [14]. Suggested that that before the use of EPP, ear of test animals should be measured in advance using a caliper. EPP was used as inflammatory agent, which was injected subcutaneously at a dose of $1 \mathrm{mg} / 20 \mathrm{uL} /$ ear. LAE and LME extracts were individually dissolved in $5 \%$ dimethyl sulfoxide in acetone at a concentration of $375 \mathrm{mg} / \mathrm{ml}$ in a similar volume of $0.5 \mathrm{ml} / 100 \mathrm{~g}$ of animal weight, which was then administered topically to the surface of the inner and outer ear. Results of observation showed that the highpoint of swelling was $4 \mathrm{hrs}$ after induction. Ear thickness was measured. Effects of $\beta$-glucan extract (laminaran) on ear edema in both control and treatment groups were compared, and the percentage inhibition was then calculated.

\section{RESULTS AND DISCUSSION}

\section{Carrageenan-induced paw edema}

Edema of hind paw induced by carrageenan has been extensively used as a model of inflammation in the search for new anti-inflammatory drugs. Edema-reducing activity was evaluated using a method, which is based on rat leg edema induced by carrageenan, modified from Winter et al. and Adeyemi et al. $[15,16]$. The results of this work were presented in Table 1.

After the carrageenan induction, wistar rat got leg swelling at the first $1 \mathrm{hr}$, in both control and treatment groups. In control group, increased swelling in control group occurred during early $5 \mathrm{hrs}$ of observation. Whereas in all treatment groups, which rat were treated with $\beta$-glucan (laminaran) extracts (LAE, LME), inhibition similarly occurred and peaked at the $3^{\text {rd }} \mathrm{hr}$. Ratheesh and Helen [17] reported that study on Ruta graveolens as an anti-inflammatory also showed maximum inhibition of inflammation after $3^{\text {rd }} \mathrm{hrs}$ of observation. This is corroborated by a report from Adeyemi et al. [16] which stated that the effects of $P$. americana extracts on carrageenan-induced edema legs are most prominent in the $3^{\text {rd }} \mathrm{hrs}$. Amdekar et al. [9] demonstrated a slight difference result in the maximum time triggering inflammation, i.e., at $4^{\text {th }} \mathrm{hrs}$, when researching the inhibition effects on inflammation by Lactobacillus casei and L. acidophilus.

The mechanism of edema production of by carrageenan is possibility due to release of prostaglandins (PG), which is in line with the release phase of prostaglandin at the $3^{\text {rd }}$ hrs [18]. The development of inflammation or edema in the legs of Wistar rat after injection of carrageenan is due to the release of histamine, serotonin, and PG [17].

LME extract significantly suppressed the Wistar rat feet edema by $81.62 \%$, followed by LAE extract, and LMEs by $73.47 \%$ and $67.35 \%$, respectively. This means that LME extract can function as an anti-inflammatory compound and even with the strongest activity as observed in this study. When compared to results of Ratheesh and Helen [17] using R. graveolens as object of the study, and the introduction of $20 \mathrm{mg} / \mathrm{kg}$ dose, results in this study demonstrated that the decrease of mice edema by $90.9 \%$ inhibition was still lower than ability of extracts LME to do so. However, the decrease is higher when compared to the results from Voveran as standard drug (72.72\%) [17]. This means that the anti-inflammatory activity of LME extracts is higher than that of Voyeran.

\section{MESA}

EPP is a material used to cause edema in addition to arachidonic acid. EPP was usually used on the ear of test animals such as mice. Noninvasive swelling test of mouse ear (MESA) is a delayed hypersensitivity model type used as a promising testing protocol for allergic contact dermatitis (ACD). The formation of ear edema of mice induced by EPP is a model useful for screening and investigating the anti-inflammatory activity of the tested substance in the acute phase of inflammation [19]. MESA allows the identification of potential of ACD for $\beta$-glucan (laminaran) at very low concentrations of applications, which could not produce ACD using other techniques.

In this study, using EPP subcutaneously injected into the Wistar rat ears, it turns out the edema response occurred very slowly, where swelling detected just after 8 hrs as shown in Table 2 .
Table 1: Edema reducing activity of $\beta$-glucan (laminaran) on Edema-hind paw of Rattus norvegicus

\begin{tabular}{llll}
\hline Observation (hour) & Sample & $\begin{array}{l}\text { Mean size of } \\
\text { edema (cm) }\end{array}$ & $\begin{array}{l}\text { Relative } \\
\text { inhibition on } \\
\text { control (\%) }\end{array}$ \\
\hline $1 \mathrm{hr}$ & Control & $0.38 \pm 0.025$ & \\
& LAE & $0.27 \pm 0.13$ & 28.95 \\
$3 \mathrm{hrs}$ & LME & $0.24 \pm 0.16$ & 36.84 \\
& Control & $0.49 \pm 0.041$ & \\
$5 \mathrm{hrs}$ & LAE & $0.13 \pm 0.08$ & 73.47 \\
& LME & $0.09 \pm 0.08$ & 81.62 \\
& Control & $0.51 \pm 0.041$ & \\
& LAE & $0.38 \pm 0.13$ & 25.49 \\
\hline
\end{tabular}

R. norvegicus: Rattus norvegicus, LAE: Laminaran acid extract, LME: Laminaran modified extract

Table 2: Edema reducing activity of $\beta$-Glucan (laminaran) on ear edema of Rattus norvegicus

\begin{tabular}{|c|c|c|c|c|}
\hline \multirow[t]{2}{*}{ Hour } & \multirow[t]{2}{*}{ Control } & \multicolumn{3}{|c|}{ Edema value (mm, $\mathrm{X} \pm \mathrm{SD}$ ) } \\
\hline & & $\begin{array}{l}\text { Phenyl } \\
\text { butazon }\end{array}$ & LAE & LME \\
\hline \multicolumn{5}{|c|}{ Right ear } \\
\hline 8 & $0.92 \pm 0.03$ & $0.78 \pm 0.07$ & $0.79 \pm 0.08$ & $0.71 \pm 0.09$ \\
\hline 12 & $0.92 \pm 0.03$ & $0.72 \pm 0.09$ & $0.75 \pm 0.08$ & $0.68 \pm 0.09$ \\
\hline \multicolumn{5}{|c|}{ Left ear } \\
\hline 8 & $0.93 \pm 0.055$ & $0.81 \pm 0.12$ & $0.79 \pm 0.05$ & $0.74 \pm 0.07$ \\
\hline 12 & $0.93 \pm 0.055$ & $0.69 \pm 0.14$ & $0.76 \pm 0.04$ & $0.72 \pm 0.08$ \\
\hline
\end{tabular}

R. norvegicus: Rattus norvegicus, LAE: Laminaran acid extract,

LME: Laminaran-modified extract, SD: Standard deviation

The thickness of edema on both right and left ears of wistar rat in the control group on $8 \mathrm{hrs}$ after the injection, reached the highest level (0.92 \pm 0:03 mm). LAE, LME extracts with better inhibition intensity better that using another commercial anti-inflammatory drug, phenylbutazone (at a dose of $1 \mathrm{mg} /$ ear). The lowest thickness of rat ear edema obtained from treatment using LME extract by $0.71 \mathrm{~mm} \pm 0$ :09 meaning that LME extracts generated significant inhibitory activity on edema formation at a dose of $375 \mathrm{mg} / \mathrm{ml} / \mathrm{ear}$, compared to other treatments did, also provided slightly higher intensity than phenylbutazone did. Thickness reduction of edema occurred on day $12^{\text {th }}$ of observation, on both the right and left ears of rat.

The occurrence of edema in the ear is caused by the release of inflammatory mediators such as histamine, serotonin, bradykinin, and PG. These mediators are able to promote vasodilation and to increase vascular permeability. Hence, it would synergistically produce edema [20]. It was known that the LME extract had inhibitory effect on edema formation. According Panthong et al. [19], the tested extract may possess anti inflammatory activity by inhibiting the release or synthesis of a variety of inflammatory mediators.

\section{CONCLUSION}

$\beta$-glucan (laminaran) LME extract exhibited edema-reducing activity which was proved by its inhibition against the right feet of carrageenan induced-edema with a percentage inhibition of $81.62 \%$ after $3 \mathrm{hrs}$ treatment. It also inhibits the wistar rat ear swelling by $0.71 \mathrm{~mm} \pm 0: 09$, which was higher than that of control, phenyl butazon. Therefore, $\beta$-glucan (laminaran) from $S$. crassifolium able to act as edema-reducing agent.

\section{ACKNOWLEDGMENT}

The Authors Thanks to Ministry of Research, Technology and Higher Education of the Republic of Indonesia Throughout the Grant of the Research. 


\section{REFERENCES}

1. Malve H. Exploring the ocean for new drug developments: Marine pharmacology. J Pharm Bioallied Sci 2016;8(2):83-91.

2. Prihanto AA, Wakayama M. Marine microorganism: An underexplored source of L-asparaginase. Adv Food Nutr Res 2016;79:1-25.

3. Chizhov AO, Dell A, Morris HR. Structural analysis of laminarans by MALDI and FAB mass spectrometry. Carbohydr Res 1998;310(3):203-10.

4. Rioux LE, Turgeon SL, Beaulieu M. Effect of season on the composition of bioactive polysaccharides from the brown seaweed Saccharina longicruris. Phytochemistry 2009;70(8):1069-75.

5. Kurniatanty I, Tan MI, Ruml T, Sumarsono SH. Potential cell proliferation inhibitor isolated from Indonesian brown algae (Phaeophyta). Int J Pharm Pharm Sci 2015;7(11):140-3.

6. Oliveira NM, Meira CL, Aguiar RM, De Oliveira DM, Moura CW, Filho SA. Antitumor effects and characterization of biosynthesized iron oxide nanoparticles using seaweeds of Gulf of Mannar. Int J Pharm Pharm Sci 2015;7:350-3.

7. Mahat MA, Patil BM. Evaluation of anti-inflammatory activity of methanol extract of Phyllanthus amarus in experimental animal models. Indian J Pharm Sci 2007;69(1):33-6.

8. Sosa S, Balick MJ, Arvigo R. Screening of the topical anti-inflammatory activity of some Central American plants. J Ethnopharmacol 2002;81(2):211-5.

9. Amdekar S, Roy P, Singh V, Kumar A, Singh R, Sharma P. Antiinflammatory activity of lactobacillus on carrageenan-induced paw edema in male wistar rats. Int J Inflam 2012;2012:752015.

10. Yvin JC, Le Vasseur F, Hud'Homme F. Use of laminarin and oligosaccharides derived therefrom in cosmetics and for preparing a skin treatment drug. US Patent. 5980 916; 1999.
11. Mohsen AM, Mohamed SF, Ali FM, El-Sayed OH. Chemical structure and antiviral activity of water-soluble sulfated polysaccharides from Surgassum latifolium. J Appl Sci Res 2007;3(10):1178-85.

12. Duffy JC, Dearden JC, Rostron C. Design, Synthesis and biological testing of a novel series of anti - inflammatory drugs. J Pharm Pharmacol 2001;531505-14.

13. Frenkel JK. Adoptive immunity to intracellular infection. J Immunol 1967;98:1309-19.

14. Nualkaew S, Rattanamanee K, Thongpraditchote S, Wongkrajang Y, Nahrstedt A. Anti-inflammatory, analgesic and wound healing activities of the leaves of Memecylon edule Roxb. J Ethnopharmacol 2009;121(2):278-81.

15. Winter CA, Risley EA, Nuss GW. Carrageenan induced edema in the hind paw of rat as an assay for anti-inflammatory activity. Proc Soc Exp Biol Med 1962;111:544-7.

16. Adeyemi OO, Okpo SO, Ogunti OO. Analgesic and anti-inflammatory effects of the aqueous extract of leaves of Persea americana Mill (Lauraceae). Fitoterapia 2002;73(5):375-80.

17. Ratheesh M, Helen A. Anti-inflammatory activity of Ruta graveolens Linn on carrageenan induced paw edema in Wistar male rats. Afr J Biotechnol 2007;6(10):1209-11.

18. Di Rosa M, Giroud JP, Willoughby DA. Studies on the mediators of the acute inflammatory response induced in rats in different sites by carrageenan and turpentine. J Pathol 1971;104(1):15-29.

19. Panthong A, Pangaoop R, Khonsung P, Chiranthanut N, Nuntasaen N, Jaitheerapapkul S, et al. Anti-inflammatory and analgesic effects of the methanol extract from garcinia wallichii choisy in animal models. Chiang Mai Med J 2009;48(3):105-15.

20. Carlson RP, O’Neill-Davis L, Chang J, Lewis AJ. Modulation of mouse ear edema by cyclooxygenase and lipooxygenase inhibitors and other pharmacologic agents. Agents Actions 1985;17:197-204. 